\title{
A oralidade no Ensino Médio: Uma análise da Base Nacional Comum Curricular
}

\author{
Orality in high school: \\ Analysis of the Base Nacional Comum Curricular
}

\author{
Edna Pagliari Brun*
}

\begin{abstract}
RESUMO: Em 2015, foi disponibilizado à opinião pública o texto da Base Nacional Comum Curricular (BNCC), cujo objetivo é possibilitar o redesenho curricular da Educação Básica. Tendo como prerrogativa as Diretrizes Curriculares Nacionais, a base comum deve privilegiar a intertextualidade entre os componentes curriculares e o direito à aprendizagem e ao desenvolvimento do estudante. Devido à importância do Documento para a redefinição dos rumos da educação no país e para a formação inicial e continuada de professores, a pesquisa, que se inscreve nos quadros da Linguística Aplicada, analisou um aspecto do ensino de língua portuguesa no Documento Oficial: a oralidade. Nessa análise, privilegiamos a modalidade falada da língua e o tratamento dado a ela na BNCC. Os primeiros resultados apontaram que o Documento apresenta um desequilíbrio acentuado na proposição de objetivos de aprendizagem da modalidade oral e da escrita, bem como na maneira como são propostos, evidenciando a possível predileção da Base pelo ensino desta em detrimento daquela.
\end{abstract}

PALAVRAS-CHAVE: Base Nacional Comum Curricular. Língua Portuguesa. Oralidade.

ABSTRACT: In 2015, the text of the Base Nacional Comum Curricular (BNCC) was made available to the public. Its goal is to enable a redesign for the basic education curriculum. With the Diretrizes Curriculares Nacionais prerogative, the common base should prioritize the intertextuality between the curricular components and the right to learning as well as the development of the student. Due to the importance of the redefinition of the direction of education in the country and for the beginner and continuing teacher, the research, which fits into the area of applied linguistics, analyzes one aspect of the teaching of portuguese language in the Official Document: the orality. In this analysis, we evince the spoken language mode and the treatment given to it in the BNCC. The first results showed that the document presents an imbalance in the learning objectives proposition of oral and writing modes, as well as in the way they are proposed, demonstrating the possible predilection of the Base for teaching one aspect at the expense of another.

KEYWORDS: Base Nacional Comum Curricular. Portuguese. Orality.

\footnotetext{
* Doutoranda em Linguagem e Educação, na Universidade Estadual de Londrina-UEL. Mestre em Linguística e Semiótica pela Universidade Federal de Mato Grosso do Sul-UFMS. Docente do Curso de Letras do Centro de Ciências Humanas e Sociais da Universidade Federal de Mato Grosso do Sul-UFMS. E-mail: ednapbrun@gmail.com.
} 


\title{
Considerações iniciais
}

Uma das soluções para o problema do baixo rendimento escolar, constatado nos resultados de avaliações oficiais ${ }^{1}$ que indicam um índice insatisfatório de desenvolvimento educacional no Brasil, estaria, segundo o Ministério da Educação (MEC), na reformulação dos currículos escolares, mas, desta vez, alicerçada na proposição de uma base nacional comum, conforme prevê a Lei de Diretrizes e Bases da Educação (LDB). Dessa feita, colocando tal proposição em prática, foi disponibilizada à opinião pública, em 2015, a primeira versão do texto da Base Nacional Comum Curricular (BNCC), cujo principal propósito é justamente possibilitar o redesenho curricular da Educação Básica (EB).

Considerando as Diretrizes Curriculares Nacionais Gerais para a Educação Básica (BRASIL, 2013), a função da BNCC (BRASIL, 2015, p. 7) é

\begin{abstract}
sinalizar percursos de aprendizagem e desenvolvimento dos estudantes ao longo da Educação Básica, compreendida pela Educação Infantil, Ensino Fundamental, anos iniciais e finais, e Ensino Médio, capazes de garantir aos sujeitos da Educação Básica parte desse direito [à educação], trata-se de uma ferramenta que vai ajudar a orientar a construção do currículo das mais de 190 mil escolas de Educação do país, espalhadas de Norte a Sul, públicas ou particulares.
\end{abstract}

Idealizada em 1988, no artigo 10 da Constituição Federal, a necessidade de uma base nacional comum para o currículo aparece prescrita desde 1996, na LDB:

Art. 26. Os currículos da educação infantil, do ensino fundamental e do ensino médio devem ter base nacional comum, a ser complementada, em cada sistema de ensino e em cada estabelecimento escolar, por uma parte diversificada, exigida pelas características regionais e locais da sociedade, da cultura, da economia e dos educandos (BRASIL, 1996, p. 19).

\footnotetext{
${ }^{1}$ Sistema Nacional de Avaliação da Educação Básica (SAEB) e Exame Nacional do Ensino Médio (ENEM).
} 
Apesar das tensões e divergências em torno de sua elaboração, a estratégia proposta no Documento para a reformulação do desenho curricular é a proposição de uma base comum de habilidades e conhecimentos essenciais para o desenvolvimento dos estudantes brasileiros, integrando os currículos de todas as escolas - públicas e privadas - e auxiliando na formulação do projeto político pedagógico dessas instituições de ensino.

Na opinião do MEC, a grande vantagem da Base passaria, primeiramente, por uma questão de equidade, isto é, todo estudante no país teria acesso ao conhecimento igualmente; e, depois, por uma questão de eficiência, pois ela promoveria o alinhamento de materiais didáticos, dos cursos de formação de professores e até mesmo da estrutura física das escolas, que poderia, segundo o órgão ministerial, ser adequada ao objetivo de aprendizagem do alunado. Contudo, apesar da aparência harmoniosa da proposição, de acordo com os primeiros pareceres do Documento, apurados a partir de consulta pública e de manifestações de estudiosos ligados à temática ${ }^{2}$, essas são algumas das dimensões mais polêmicas da Base.

A BNCC deverá constituir parte do currículo das escolas, representando $60 \%$ dele, enquanto os outros $40 \%$ devem ser destinados aos conteúdos adequados às regiões do país - é a "parte diversificada" do currículo a ser construída pelas redes de ensino "em diálogo com a primeira [a parte comum] e com a realidade de cada escola" (BRASIL, 2015, p. 15).

Essa determinação talvez seja uma tentativa de evitar a mesma polêmica, em torno da centralização/descentralização das políticas curriculares, ocorrida quando da proposição dos Parâmetros Curriculares Nacionais (PCN)3, no final da

\footnotetext{
2 Vários grupos de pesquisa e associações, tais como Grupo de Pesquisa Interinstitucional (EMpesquisa), Associação Nacional de Pós-Graduação e Pesquisa em Educação (ANPED), Associação de Linguística Aplicada do Brasil (ALAB), Associação Brasileira de Linguistas (ABRALIN), entre outros, têm manifestado críticas e opiniões sobre diversos pontos da BNCC. Os pareceres e sugestões podem ser acessados no site http://basenacionalcomum.mec.gov.br/\#/site/inicio, e no endereço eletrônico dessas entidades na internet.

${ }^{3}$ As menções aos PCN, neste artigo, não configuram uma comparação à BNCC ou a intenção de reunir esses documentos em um bloco homogêneo, uma vez que são diferentes e não harmônicos
} 
década de 1990. De acordo com Marinho (2007), naquela ocasião, o MEC, sob o argumento da necessidade de se garantir um mínimo de qualidade para todas as escolas brasileiras, evitando assim as disparidades evidenciadas em avaliações oficiais, tomou para si a responsabilidade de definir programas e currículos para a EB, retirando das secretarias de educação municipais e estaduais a função que outrora era designada a esses órgãos. Apesar dessa aparente parceria e da convocação desses órgãos para participarem da elaboração da BNCC, a imposição de uma parte comum do currículo ${ }^{4}$, em conformidade, portanto, com uma lógica descendente e autoritária de instauração de reformas educacionais (BRONCKART, 2010), já transparece uma medida totalitária.

Também tentando evitar as críticas de que a BNCC não foi amplamente discutida antes de sua implementação, as mesmas críticas sofridas quando da implantação dos PCN, o MEC, desta vez, disponibilizou o texto da Base na internet para conhecimento em larga escala e para proposição de sugestões. A despeito dessa providência, a metodologia adotada, na elaboração do Documento, não deu espaço para o debate público com a participação direta e efetiva da comunidade escolar, para a qual o tema em pauta é tão relevante. Desse modo, professores, gestores e estudantes das escolas públicas, que muito tinham/têm a contribuir, não foram consultados, por exemplo, sobre quais critérios deveriam ser levados em conta para a confecção de uma base comum curricular. De acordo com declarações dos responsáveis pelo órgão federal, uma comissão nacional formada por 116 profissionais teria sido responsável pela elaboração do texto da Documento, procedimento que corrobora a preferência do MEC pela busca por especialistas e pela consulta fria e impessoal à sociedade.

Dessa força de trabalho, originou-se a primeira versão do texto da BNCC, disponibilizada à apreciação pública, pela internet, no segundo semestre de 2015,

entre si. Trata-se somente de observações circunstanciais a respeito da situação de recepção de ambos.

${ }^{4}$ Estudos vêm alertando para o fato de que os conteúdos propostos como base para o ensino ultrapassariam $60 \%$ do currículo escolar, não deixando espaço para a adaptação relativa aos $40 \%$ restantes. Disponível em: <movimentopelabase.org.br>. 
que ora investigamos. Com esta pesquisa, nossa intenção é contribuir com discussões a respeito das normas/prescrições que constam no Documento Oficial, no tocante à articulação dos objetivos ali consignados para o ensino de língua portuguesa, considerando um de seus domínios prioritários: a oralidade.

Estudos das décadas de 1960 e 1970 já cogitavam a relevância da modalidade oral no ensino de língua, sob argumentos de que o cidadão depende muito mais da língua falada do que da língua escrita para sua vida social (RODRIGUES, 1966), ou ainda de que o seu uso é uma forma de desenvolver outras habilidades além da expressão oral (GENOUVRIER; PEYTARD, 1974).

Contudo, a ideia de um trabalho voltado para a oralidade no ensino de língua portuguesa ganha mais força, no final da década de 1980, em decorrência de teorizações fundamentadas nos resultados de dois projetos importantes de descrição da língua falada no Brasil: o projeto Norma Urbana Culta e o projeto Gramática do Português Falado (CASTILHO, 2005). Considerando esses estudos ${ }^{5}$, a língua falada adentra os meios escolares com o objetivo de possibilitar ao aluno a reflexão sobre a língua e o entendimento dos processos constitutivos da linguagem, partindo do que ele já sabia (a variedade linguística falada pelas camadas socioculturais baixas, por exemplo). Assim, a modalidade oral passou a ser vista como uma alternativa de ensino para levar o alunado a atingir com mais eficácia a língua escrita.

Desde então, equívocos perpassaram o ensino de língua materna. O que, a princípio, deveria ser entendido como mais uma possibilidade de ensino da língua passou a ser confundido com desprezo às convenções da língua escrita e com descarte da norma padrão, e, por causa disso, sofreu muitas críticas negativas. Paulatinamente, com a publicação de resultados de estudos ${ }^{6}$ a respeito das singularidades da língua falada e de suas diferenças e semelhanças

\footnotetext{
${ }^{5}$ Castilho (1990, 1993), Ilari (1992), Castilho e Basílio (1996), Kato (1996), Koch (1996), entre outros.

${ }^{6}$ Koch (1998); Marcuschi (2001, 2006a); Dionísio (2006), por exemplo.
} 
com a língua escrita, alguns equívocos foram desfeitos ${ }^{7}$, pelo menos, em cursos de formação de professores que têm como premissa os estudos da linguagem, no entanto, outras dificuldades surgiram, entre elas, o desconhecimento de alternativas pedagógicas para o ensino da oralidade ${ }^{8}$.

Nesse sentido, o primeiro entrave está na dificuldade de definição do oral, segundo uma concepção mais complexa do fenômeno, e no não reconhecimento da língua oral como um objeto autônomo, explícito e consciente de ensino.

Diante da multiplicidade de manifestações da oralidade nas práticas sociais, o segundo obstáculo, consequência do primeiro, é relativo a quais dimensões do oral ensinar e como ensiná-las, ou seja, dificuldades ligadas à seleção dos objetos e à metodologia de ensino. Apesar de estar presente, regularmente, em sala de aula (na correção de exercícios, nas leituras de instruções de tarefas, nas rotinas em geral), o espaço para o ensino da oralidade ainda é limitado na escola: ou ocorre tendo a fala como dependente da escrita, isto é, reproduzindo-a em atividades de oralização da escrita (MARCUSCHI, 2001) - atividades com base no equívoco de que o som é condição suficiente para definir (e ensinar) língua oral -, ou sem intervenção sistemática, de modo a priorizar o ensino daquilo que o aluno já domina, ou seja, o que os usuários da língua aprendem naturalmente em situações de interação (DOLZ; SCHNEUWLY, 2004).

Considerando esse contexto específico e a relevância da BNCC não somente para a sociedade em geral, mas, particularmente, para as áreas que tratam do ensino e da aprendizagem de língua portuguesa, o propósito de nossa pesquisa foi analisar os "objetivos de aprendizagem" (BRASIL, 2015) propostos pela Base para o ensino da modalidade oral da língua. Nosso objetivo foi verificar

\footnotetext{
7 Há setores da sociedade em que esses equívocos ainda permanecem e as críticas continuam, em virtude, principalmente, da confusão entre língua e gramática normativa, entre língua e norma escrita, e supervalorização da escrita em detrimento da fala.

${ }^{8}$ Os PCN (BRASIL, 1997, 1998, 2000) prescrevem o ensino da oralidade, mas abordam a linguagem oral de forma genérica e não propõem ou discutem alternativas para seu ensino.
} 
o tratamento dado ao ensino da língua falada e à oralidade na BNCC para o ensino de língua portuguesa no Ensino Médio (EM).

Nossa opção por esse eixo de ensino apoia-se nas constatações, apresentadas há pouco, sobre como a oralidade vem sendo tratada na escola; nas pesquisas de Magalhães (2008) as quais apontam para o fato de que, desde o lançamento dos PCN, ele fica em segundo plano em relação ao eixo de ensino da escrita. Já a escolha do EM justifica-se pelo baixo rendimento escolar dessa etapa, confirmado nos resultados do Índice de Desenvolvimento da Educação Básica-Ideb/2015 ${ }^{9}$, uma vez que uma das justificativas para a elaboração da BNCC é a melhoria desses indicadores; pela carga de problemas que atinge esse nível de escolaridade, como o alto índice de evasão escolar; e pelo número mais reduzido de pesquisas nessa área em relação ao Ensino Fundamental (EF).

Visando à análise do Documento, propusemos quatro objetivos específicos:

Quadro 1 - Objetivos específicos da pesquisa

(1) Identificar, nos objetivos de aprendizagem, os critérios de seleção e proposição dos objetos de ensino/conteúdos para o ensino da modalidade oral da língua no EM que deverão fazer parte do currículo escolar;

(2) Identificar os aportes teóricos que embasam a aprendizagem referente à oralidade;

(3) Identificar o(s) critério(s) de progressão dos objetos de ensino/conteúdos nas etapas do EM; e

(4) Verificar como os objetos/conteúdos selecionados favorecem o ensino/aprendizagem da modalidade oral nas etapas do EM.

Fonte: a autora

Para apresentarmos os resultados de nossa investigação, organizamos o artigo da seguinte forma: nesta introdução, com vistas nos objetivos da pesquisa, discutimos aspectos gerais da construção da BNCC e do tratamento da oralidade na escola; nos próximos tópicos, expusemos, primeiramente, a fundamentação teórica que trata de noções conceituais relativas à oralidade e seu ensino, as quais dão suporte à análise; e, posteriormente, os procedimentos metodológicos

\footnotetext{
${ }^{9}$ Disponíveis em:

<http://ideb.inep.gov.br/resultado/resultado/resultadoBrasil.seam?cid=7165883>.
} 
norteadores do percurso analítico; na sequência, detalhamos pontos específicos da análise do tratamento dispensado pela Base ao eixo da oralidade no EM; finalizando, apresentamos algumas considerações a respeito do Documento Oficial analisado e as referências citadas ao longo do artigo.

Assim, passaremos, a seguir, para os aportes teóricos.

\section{Oralidade letrada e ensino: fundamentação teórica}

O conceito de letramento está intimamente ligado à oralidade. Segundo Marcuschi (2001, p. 25), oralidade e letramento ${ }^{10}$ referem-se a práticas sociais interativas que envolvem a fala e a escrita. A primeira é definida como "uma forma de produção textual-discursiva para fins comunicativos na modalidade oral"; e a segunda, "um modo de produção textual-discursiva para fins comunicativos com certas especificidades materiais", trata-se de "uma modalidade de uso da língua complementar à fala".

Para o autor, a língua falada seria então ponto de partida para o ensino, e a escrita, o ponto de chegada, não significando, contudo, que, no ensino, a primeira deva ser privilegiada apenas na etapa inicial de escolarização e a segunda, na etapa final, pois a língua se manifesta no continuum de gêneros de textos na relação entre fala e escrita. Corroborando essa ressalva, Koch (1997) esclarece que, no continuum fala-escrita, há textos orais mais próximos da escrita formal (discurso político, conferências, entrevistas de profissionais) e textos escritos mais próximos à fala informal (bilhetes, e-mails informais, mensagens de celulares, piadas), havendo ainda tipos mistos e muitos outros intermediários ${ }^{11}$.

Ainda quanto ao ensino da língua falada, Kato $(1986$, p. 7) afirma que "a chamada norma padrão, ou língua falada culta, é consequência do letramento,

\footnotetext{
${ }^{10}$ A definição de letramento proposta por Kleiman (2008, p. 97), "práticas relacionadas com a escrita em toda atividade da vida social", articula-se à de Marcuschi, considerada nesta pesquisa. ${ }^{11}$ Marcuschi (2008, p. 194-197) apresenta uma extensa relação de gêneros das modalidades escrita e falada e um esquema com a distribuição de alguns deles no continuum da relação falaescrita.
} 
motivo por que, indiretamente, é função da escola desenvolver no aluno o domínio da linguagem falada institucionalmente aceita", ou a oralidade letrada.

Por isso, o desenvolvimento da expressão oral, visando à oralidade letrada, por meio de atividades variadas de reconhecimento e domínio de gêneros textuais orais, de forma a levar os aprendizes a desenvolverem habilidades que atendam a demandas sociais pela linguagem, é um dos objetivos do ensino de língua portuguesa na EB. Ou seja, a escola deve formar o aluno de modo que ele seja capaz de agir em esferas sociais, em situações públicas formais de comunicação, utilizando a língua não apenas na modalidade escrita, mas também na oral, tornando-se bimodal (MARCUSCHI, 2001), isto é, fluente nas duas modalidades da língua. Dessa forma, o trabalho exclusivo com a escrita não promove um ensino eficiente de língua.

Apesar de essas considerações serem consenso em diversas áreas dos Estudos da Linguagem ${ }^{12}$ - fundamentadas na concepção de linguagem como interação -, o trabalho voltado para a oralidade ainda repercute pouco na escola, que continua privilegiando sobremaneira o trabalho com o letramento da letra, ou ensinando o oral de maneira equivocada, conforme comentamos anteriormente.

Vários motivos podem explicar a supervalorização da escrita em relação à fala, originários de crenças antigas, cristalizadas, a partir dos efeitos da aquisição da escrita no desenvolvimento das culturas orais. Gnerre (1991, p. 41, 47) afirma que a "aceitação básica do valor indiscutivelmente positivo da escrita foi intocável durante décadas", sendo "difícil achar qualquer avaliação explícita dos aspectos positivos das culturas orais, às vezes definidas de forma negativa como culturas 'sem tradição escrita"'.

Um desses motivos vem da crença segundo a qual a fala seria sempre mais coloquial que a escrita e somente esta veicularia textos produzidos em registros formais (RAMOS, 1999), por isso, o erro é considerado natural na

\footnotetext{
${ }^{12}$ Linguística Aplicada, Sociolinguística, Linguística Textual, Pragmática, Psicolinguística, Semântica Enunciativa, Análise da Conversação, Análise do Discurso, além de diversas correntes interacionistas.
} 
primeira, enquanto não é tolerado na segunda. Vista dessa forma, a modalidade oral é, negativamente, considerada comum, popular, pobre, mal estruturada, enquanto a modalidade escrita seria padrão absoluto de correção. Essa postura alimentou/alimenta o engano de se relacionar escrita a padrão e fala a nãopadrão. Todavia, o que determina o nível de formalidade dos textos, orais e escritos, e o registro a ser utilizado é o gênero textual/discursivo, ou melhor, a situação comunicativa e as condições de produção dos textos de gêneros diversos.

A falta de compreensão de que as duas modalidades apresentam semelhanças e diferenças muito tênues entre si, determinadas pelos gêneros que as manifestam, também contribui para se considerar uma superior à outra. Marcuschi (2008) pondera, no entanto, que, do ponto de vista da semiologia, essas modalidades apresentam singularidades que imprimem diferenças bastante acentuadas entre elas. Desconhecer isso tem como consequência, por exemplo, considerar a escrita como representação unívoca da fala, confusão que persiste. Segundo o autor, não há uma correspondência direta entre pronúncia e grafia, bem como não deixa de ser um problema reproduzir na escrita aspectos ligados à prosódia. Isso pode ser verificado na transcrição do oral, que exige várias transformações (transcodificação, retextualização ${ }^{13}$ ). Apesar disso, língua falada e língua escrita não devem ser tratadas de forma dicotômica, pois integram o mesmo sistema linguístico, compartilhando o mesmo léxico e a mesma gramática: são modalidades de uma só língua.

Desfeitos alguns equívocos, é necessário compreender que a finalidade geral do ensino de língua portuguesa é desenvolver a competência discursiva do aluno. Nesse sentido, Schneuwly (2004, p. 135) formula com os seguintes princípios básicos para o ensino de língua:

13 Transcodificação é a passagem do sonoro para o gráfico, enquanto retextualização é a transformação na perspectiva de uma das modalidades, uma adaptação no texto (MARCUSCHI, 2001). 


\begin{abstract}
levar os alunos a conhecer e dominar sua língua, nas situações as mais diversas, inclusive em situações escolares; desenvolver, nos alunos, uma relação consciente e voluntária com seu próprio comportamento linguístico, fornecendo-lhes instrumentos eficazes para melhorar suas capacidades de escrever e de falar; e construir com os alunos uma representação das atividades de escrita e fala, em situações complexas, como produto de um trabalho, de uma lenta elaboração.
\end{abstract}

No âmbito da oralidade, os meios acadêmicos ${ }^{14}$ já demonstraram que a maneira mais adequada de atingir esse objetivo é tomar práticas de linguagem que se realizam, prioritariamente, pelo uso da modalidade oral da língua, como objetos do trabalho escolar, devendo o professor propor atividades variadas de escuta, produção e análise de gêneros orais.

A partir disso, algumas questões são levantadas: Que gêneros orais trabalhar e por quê? Que relação estabelecer entre eles e a escrita? Que relação estabelecer entre fala e escuta? O que analisar nesses gêneros?

Dolz e Schneuwly (2004), Marcuschi (2003, 2006b, 2008), entre outros, são unânimes em afirmar que o trabalho docente deve privilegiar gêneros públicos do cotidiano, gêneros secundários ${ }^{15}$ (BAKHTIN, 2003), proporcionando ao aluno a ampliação de conhecimentos discursivos, semânticos e gramaticais envolvidos na construção de sentidos.

Tendo em vista os estudos desses pesquisadores, Melo e Cavalcante (2007, p. 83-87) tomam a modalidade falada como objeto de ensino, a partir de um trabalho de reflexão que articula "questões relacionadas a situações comunicativas, estratégias organizacionais de interação próprias de cada gênero, processos de compreensão etc." Para isso, sugerem três grupos de parâmetros de análise de gêneros orais: (1) extralinguísticos (grau de publicidade, de intimidade dos participantes, de cooperação, de participação emocional, de

14 Kato (1986), Kleiman (1995), Koch (1998), Castilho (2000), Dionísio, Machado e Bezerra (2003), entre outros.

${ }^{15}$ Bakhtin (2003) classifica os gêneros em primários e secundários. Os primários aludem a situações de interação menos elaboradas e mais informais do que as situações nas quais os secundários são produzidos. Estes são mais complexos e circulam por esferas mais ideologizadas. Um bilhete, um diálogo cotidiano são exemplos de gêneros primários; um romance, uma palestra são identificados como gêneros secundários. 
proximidade física dos parceiros da comunicação, de cooperação, de espontaneidade, fixação temática); (2) paralinguísticos e cinésicos (qualidade da voz, elocução e pausas, risos/suspiros/choro/irritação; atitudes corporais, gestos, troca de olhares, mímicas faciais); e (3) linguístico-discursivos (marcadores conversacionais, repetições e paráfrases, correções, hesitações, digressões, expressões formulaicas, atos de fala/estratégias de polidez). As autoras enfatizam, ainda, que o objetivo da análise não é apenas levar os alunos a identificar esses parâmetros, mas também a refletir por que eles ocorrem ou não no discurso, deixando clara a "associação entre aquilo que se manifesta na superfície textual e as motivações sociais, culturais, situacionais, cognitivas que condicionam as práticas sociais" (MELO; CAVALCANTE, 2007, p. 91).

Marcuschi (2001) sugere atividades de escuta de textos que favoreçam o entendimento da relação oral-escrita, por meio da transcrição e da retextualização de textos orais que coloquem os alunos em situações reais de interlocução. Tarefas desse tipo possibilitam identificar características próprias da fala, aplicar os parâmetros de análise discutidos por Melo e Cavalcante (2007), analisar interferências e adequações resultantes do processo de transformação de uma modalidade para a outra, possibilitando a reflexão sobre a língua falada.

Ao defender uma "pedagogia do oral", Magalhães (2008, p. 147) sugere para o trabalho docente com a oralidade atividades que envolvam a escuta e a produção (usos) de textos que também favoreçam a análise da língua (reflexão). Segundo a autora, nessas atividades, "são construídos conhecimentos e conceitos sobre a linguagem, sobre os papéis sociais envolvidos na interação, bem como a inserção do aluno em atividades de oralidade letrada". Para ela, as atividades de escuta expõem o aluno a situações reais de interlocução e de uso da modalidade oral, permitindo ao estudante analisar as marcas típicas da fala. Já as atividades de produção são aquelas que o orientam tanto para a preparação prévia para o uso da fala quanto para seu uso específico. São, portanto, atividades que visam à compreensão e à análise do texto falado, ou seja, por meio delas, a língua está em foco no uso e na reflexão. 
Dessa forma, a partir da fundamentação teórica, o ensino da oralidade deve nortear-se pelos seguintes aspectos: (1) o aluno também deve ser capacitado para atuar em práticas sociais cuja mediação seja a modalidade oral da língua; (2) as atividades escolares devem privilegiar o trabalho sistemático da expressão oral (escuta, produção e análise); (3) o aluno deve aprender a organizar/planejar sua fala de acordo com as mais diversas situações de interação; e (4) o ensino da oralidade deve privilegiar gêneros orais públicos.

Tendo em vista o objetivo da pesquisa e sua fundamentação teórica, explicaremos, a seguir, os procedimentos metodológicos que guiaram o percurso analítico da BNCC.

\section{BNCC e oralidade: procedimentos metodológicos}

Apesar da abrangência da BNCC, apresentamos, neste artigo, conforme já anunciamos, os resultados de uma análise cujo foco foram os "objetivos de aprendizagem" (BRASIL, 2015) propostos para o trabalho docente com a oralidade. $\mathrm{O}$ objetivo da pesquisa, ora retratada, foi verificar o tratamento dado ao ensino da língua falada e à oralidade no EM pelo Documento.

Considerando o objeto - a oralidade e a forma como o ensino da modalidade oral da língua está prescrito na BNCC - e os objetivos da pesquisa (Quadro 1), quatro perguntas nos guiaram na análise e definiram os demais elementos organizacionais da pesquisa: 
Quadro 2 - Elementos organizadores da pesquisa

\begin{tabular}{|c|l|c|}
\hline Perguntas & \multicolumn{1}{|c|}{ Instrumento } & \multicolumn{1}{c|}{ Corpus } \\
\hline $\begin{array}{c}\text { (1) Quais são os critérios de seleção e proposição } \\
\text { dos objetos de ensino/conteúdos para o } \\
\text { ensino da modalidade oral da língua no EM } \\
\text { que deverão fazer parte do currículo escolar? }\end{array}$ & & \\
(2) Quais são os aportes teóricos que embasam a & & \\
aprendizagem referente à oralidade? & $\begin{array}{l}\text { Recorte do texto } \\
\text { da BNCC que trata }\end{array}$ & $\begin{array}{c}\text { Objetivos de } \\
\text { aprendizagem } \\
\text { do componente } \\
\text { curricular Língua }\end{array}$ \\
(3) Quais são o(s) critério(s) de progressão dos & da oralidade no & Portuguesa (LP) \\
objetos de ensino/conteúdos nas etapas do & contexto do EM & $\begin{array}{c}\text { Para o ensino da } \\
\text { modalidade oral }\end{array}$ \\
EM? & & \\
(4) De que maneira os objetos/conteúdos & & \\
selecionados favorecem o & & \\
ensino/aprendizagem da modalidade oral nas & & \\
etapas do EM? & & \\
\hline
\end{tabular}

Fonte: a autora

Pelas informações do Documento, inferimos que a estrutura do componente curricular LP está organizada em "práticas", "eixos" e "objetivos de aprendizagem". Para selecionar os dados, partimos, primeiramente, da explicitação de que os objetivos gerais pertinentes ao componente LP são balizados na BNCC por "eixos de ensino" - oralidade, leitura, escrita e análise linguística - (BRASIL, 2015, p. 34), ou seja, os eixos de uso da língua e de reflexão sobre os fatos da língua.

Fixando nosso olhar no ensino da língua falada, o passo seguinte foi selecionar os objetivos de aprendizagem referentes aos eixos de uso da modalidade falada e de reflexão sobre ela. Porém, a observação atenta do Documento levou-nos a desistir desse procedimento metodológico. Alteramos o critério de seleção dos dados, pois verificamos que a proposta inicial de uma estrutura organizada em eixos de ensino, cogitada nos objetivos gerais do componente $L P$, desaparece nos objetivos de aprendizagem, elencados pelos anos das etapas escolares, prevalecendo a disposição desses objetivos em "práticas sociais" (das quais trataremos na análise). Essa reorganização apresentada pela BNCC dificultou tanto a identificação quanto a seleção dos objetos de ensino, considerando eixos como critério. 
Selecionamos os dados, então, a partir do total de "objetivos de aprendizagem" consignados para o componente curricular LP no EM: 45 objetivos $^{16}$, distribuídos pelos 3 anos, dispostos no conjunto dessas "práticas sociais" (BRASIL, 2015, p. 61-66).

Para selecionar os objetivos de aprendizagem específicos para o ensino da modalidade oral, procuramos por objetivos/objetos/procedimentos que de alguma forma tivessem relação com o ensino da oralidade/fala, como a menção a gêneros de textos orais, ao suporte desses gêneros, à esfera em que circulam. Com esse critério de seleção, identificamos os 10 objetivos de aprendizagem (Quadro 3), dispostos em 03 práticas sociais, que compuseram o corpus da pesquisa.

Para a categorização e análise desses dados, utilizamos a proposta de Magalhães (2008) e os parâmetros sugeridos por Melo e Cavalcante (2007), expostos na fundamentação teórica, observando a possibilidade de proposição de atividades de oralidade que contemplem a escuta, a produção e a análise de gêneros públicos orais, de modo a proporcionar ao aluno o uso, o treinamento e a reflexão sobre questões relacionadas a situações comunicativas, estratégias organizacionais de interação próprias de cada gênero, processos de compreensão etc.

Partindo do pressuposto de que os gêneros orais precisam ser produzidos e escutados para que sejam privilegiadas atividades de análise linguística, primeiramente, identificamos e classificamos os objetivos passíveis de serem atingidos por meio da escuta do texto oral ("interpretar", "reconhecer", "comparar", "analisar") e por meio da produção ("produzir") com a ressalva de que "interpretar", "reconhecer", "comparar", "analisar" também caracterizam objetivos passíveis de serem alcançados por intermédio da produção do texto oral, mas para esta optamos por categorizar os objetivos em que estivesse clara a produção.

\footnotetext{
${ }^{16}$ Para o EF são consignados 234 objetivos (BRASIL, 2015, p. 41-60).
} 
Em seguida, observamos quais aspectos da oralidade, destacados nos 10 objetivos selecionados para compor o corpus, promoveriam (ou não) oportunidades de reflexão sobre a língua falada.

Delineados os procedimentos metodológicos, o próximo tópico, destinado à análise, foi dividido em dois momentos de modo a responder às nossas perguntas de pesquisa (Quadro 2). Assim, no primeiro momento, dedicamo-nos a responder às perguntas (1), (2) e (3); e, no segundo, à pergunta (4).

Vejamos o primeiro momento da análise.

\section{A oralidade na BNCC: uma análise da proposta de ensino para o EM}

Com base na fundamentação teórica acerca da modalidade oral da língua e de suas possibilidades de estudo/ensino, fizemos uma análise da BNCC, a fim de verificar a proposta do Documento para o desenvolvimento da oralidade letrada de alunos do EM.

Uma observação no modo como a Base está estruturada permitiu aferir que os termos "princípios" e "direitos", os quais, segundo o Documento, deveriam nortear a reformulação dos currículos (BRASIL, 2015, p. 7), acabam traduzindose em um conjunto bastante amplo de objetivos gerais e de aprendizagem ${ }^{17}$ para cada uma das áreas do conhecimento (Linguagens, Matemática, Ciências da Natureza e Ciências Humanas), para cada um dos componentes curriculares que as compõe (no caso da área de Linguagens, para Língua Portuguesa, Língua Estrangeira Moderna, Arte e Educação Física), em cada um dos níveis de ensino (EI, EF e EM). Para explicar melhor essa organização, reproduzimos, no Quadro 3, um excerto do sumário do Documento, referente à área de Linguagens e ao componente LP:

\footnotetext{
${ }^{17}$ Apenas a Educação Infantil (EI) destoa dessa organização. Para essa etapa, são apresentados "direitos de aprendizagem", "campos de experiências" e "objetivos de aprendizagem" (BRASIL, 2015, p. 18-28).
} 
A oralidade no Ensino Médio:

Uma análise da Base Nacional Comum Curricular 
Quadro 3 - Excerto do sumário da BNCC

\begin{tabular}{|c|}
\hline A Área de Linguagens \\
\hline 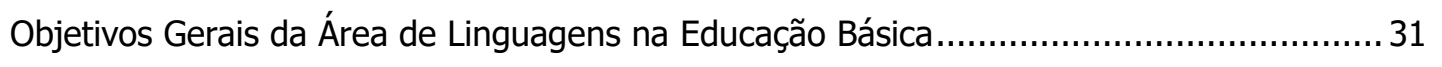 \\
\hline 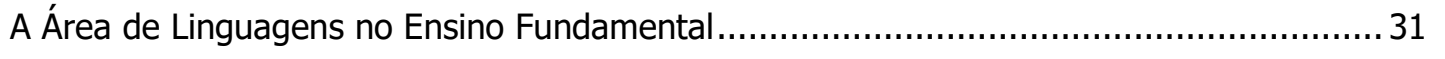 \\
\hline Objetivos Gerais da Área de Linguagens no Ensino Fundamental ...................................... 33 \\
\hline 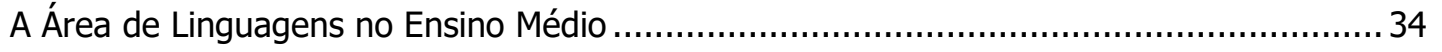 \\
\hline Os Objetivos Gerais da Área de Linguagens no Ensino Médio......................................... 35 \\
\hline Componente Curricular Língua Portuguesa ... \\
\hline Objetivos Gerais do Componente Curricular Língua Portuguesa na Educação Básica .......... 41 \\
\hline Objetivos de Aprendizagem do Componente Curricular Língua Portuguesa no \\
\hline Ensino Fundamental.. \\
\hline Objetivos de Aprendizagem do C \\
\hline
\end{tabular}
Fonte: Brasil (2015, p. 4-7)

Essa estruturação parece indicar que o núcleo organizador da BNCC é pautado em objetivos e não em princípios ou em direitos de aprendizagem, uma vez que estes acabam diluídos em meio à profusão daqueles.

Os 45 objetivos de aprendizagem, relativos ao componente curricular LP para o EM, são acompanhados por um conjunto de exemplos, ora semelhantes a procedimentos, ora a objetos de ensino/conteúdos, distribuídos em 06 "práticas sociais" - Práticas da Vida Cotidiana, Artístico-Literárias, Político-Cidadãs, Investigativas, do Mundo do Trabalho, Culturais das Tecnologias de Informação e Comunicação (BRASIL, 2015, p. 61-66) -, que revelam certa incoerência, pois práticas investigativas, por exemplo, deveriam perpassar as demais; por sua vez, práticas político-cidadãs deveriam estar pressupostas nas práticas da vida cotidiana. A partir do $5^{\circ}$ ano, as práticas cotidianas desaparecem, ou seja, perdem importância, dando a falsa impressão de que somente os alunos da EI e dos primeiros anos do EF se expressam na vida cotidiana.

Os critérios de seleção e proposição dos objetivos gerais da área de Linguagens e dos objetivos de aprendizagem do componente LP não são especificados. Tampouco há referência a conceitos de elementos fundamentais (e primordiais para os professores que ensinam língua portuguesa), tais como os 
que dizem respeito ao nosso objeto de investigação: concepções de fala, escrita, oralidade. O Documento revela ainda alguma confusão na utilização de determinados termos e/ou na forma como são empregados. Por exemplo, o emprego de oralidade como sinônimo de língua falada: "[...] a criança já participa de interações que envolvem os usos de escrita, oralidade $[. . .]^{\prime \prime}$. Quando se fala em usos, a alusão é a modalidades da língua, portanto, escrita e fala (MARCUSCHI, 2001). Referências bibliográficas também não são apresentadas. A soma dessas constatações aparenta certo descuido do Documento com relação aos aportes teóricos que fundamentam o ensino de língua.

Do mesmo modo como não é possível explicar com exatidão os critérios de seleção e proposição, também não é possível explicar os critérios de distribuição desses objetivos pelos anos do EM, pois essas informações não estão claras no Documento. Um exemplo disso diz respeito ao objetivo, atribuído às práticas do mundo do trabalho, que propõe o ensino do gênero entrevista de trabalho para o $2^{\circ}$ ano do EM e não para o $3^{\circ}$ - momento em que os alunos encerram a EB, quando muitos vão em busca de emprego, atendendo, assim, a um dos critérios de admissão de muitas empresas.

A seguir, o segundo momento da análise.

\section{Os objetivos de aprendizagem da BNCC: uma análise dos objetos de ensino da oralidade}

Devido à organização dos objetivos de aprendizagem em "práticas sociais" e não por eixos de ensino, conforme explicamos nos procedimentos metodológicos e no primeiro momento da análise, nem todos os objetivos que selecionamos (Quadro 4), no conjunto das "práticas" do EM, são voltados exclusiva ou claramente para a oralidade, mas mencionam tanto a modalidade oral como a escrita, sem que estejam, todavia, articuladas, ou que possibilitem a proposição de atividades com o objetivo de refletir sobre gêneros do continuum fala-escrita (KOCH, 1997). Essa constatação indica que os objetivos de 
aprendizagem propostos para o componente LP se aplicam tanto para uma quanto para outra modalidade, indistintamente, apesar das singularidades de cada uma.

Esses objetivos, correlatos aos dados selecionados, foram organizados, no Quadro 4, pelas "práticas" a que correspondem e identificados da mesma forma como aparecem na BNCC: as duas primeiras letras indicam a área de conhecimento (Linguagem), as duas seguintes, o componente curricular (LP), o primeiro algarismo refere-se ao ano de escolaridade do $\operatorname{EM}\left(1^{\circ}, 2^{\circ}\right.$ e $\left.3^{\circ}\right)$ e os demais identificam o objetivo de aprendizagem.

Quadro 4 - Objetivos de Aprendizagem priorizados na BNCC para o ensino da modalidade oral

\section{Objetivos de aprendizagem - EM}

\section{PRÁTICAS POLÍTICO-CIDADÃS}

LILP1007. Interpretar textos (orais e escritos) da esfera jornalística voltados ao relato de acontecimentos (como notícias e reportagens), analisando aspectos relativos ao tratamento da informação (como a ordenação de eventos, as escolhas lexicais, o efeito de imparcialidade do relato).

LILP1008. Reconhecer os componentes de uma estrutura argumentativa (como contextualização, hipóteses, tese, argumento, contra-argumento, conclusão) e identificar diferentes procedimentos argumentativos, em gêneros como editoriais, debates televisivos, entrevistas etc.

LILP1010. Produzir textos argumentativos orais e escritos, atentando especialmente para a utilização de diferentes procedimentos argumentativos (como exemplificação, citação de autoridade, exposição de dados empíricos).

LILP2004. Analisar a estrutura composicional de textos da esfera jornalística voltados ao relato de acontecimentos (como notícias, reportagens, entrevistas), considerando sua veiculação em diferentes suportes e mídias.

LILP2005. Analisar o percurso argumentativo de gêneros orais e escritos da ordem do argumentar, considerando seus recursos coesivos (operadores argumentativos de causalidade, oposição, conclusão, ressalva etc.) e, no caso do texto escrito, também os critérios de paragrafação.

LILP3004. Comparar textos da esfera jornalística voltados ao relato de acontecimentos (como notícias, reportagens, entrevistas) veiculados em diferentes mídias (impressa, audiovisual, digital), considerando semelhanças e diferenças no tratamento da informação.

LILP3005. Analisar em textos argumentativos orais e escritos o uso estratégico de recursos persuasivos, como a elaboração do título, a explicitação ou a ocultação de fontes de informação, o uso de recursos de assertividade ou atenuação de posicionamentos assumidos.

LILP3006. Produzir textos argumentativos e contra-argumentativos orais e escritos, atentando para estratégias de persuasão como a elaboração do título, recursos de assertividade ou atenuação dos posicionamentos).

\section{PRÁTICAS INVESTIGATIVAS}


LILP1013. Produzir roteiros para exposição oral de resultados de estudos e pesquisas em seminários, feiras de ciências e outros eventos escolares e acadêmicos, bem como avaliar a atuação nas exposições orais próprias e dos colegas.

\section{PRÁTICAS DO MUNDO DO TRABALHO}

LILP2014. Analisar o gênero entrevista de trabalho: o conteúdo (o que se fala), como se fala (as convenções do discurso), a relação dos interlocutores (os papéis desempenhados pelo entrevistado e entrevistador), a linguagem corporal, a fluência verbal, compreendendo a entrevista como ferramenta importante em processos seletivos.

Fonte: a autora, elaborado a partir de Brasil (2015, p. 61-66, grifos nossos)

Esses dados apontaram uma disparidade muito grande entre os objetos de ensino voltados para ensino da língua falada e para o ensino da língua escrita, pois, dos 45 objetivos de aprendizagem de língua portuguesa propostos para 0 EM, apenas 10 se referem, de alguma forma, à modalidade oral - 04 são propostos para o $1^{\circ}$ ano, 03, para o 20, e 03, para o $3^{\circ}$ (Quadro 4). Apesar de certo equilíbrio na distribuição dos objetivos pelas etapas desse nível de escolaridade, subentende-se, por esse número de objetivos, que os alunos do EM devem ser mais expostos a práticas de linguagens na modalidade escrita. Talvez, ainda permaneça a crença da superioridade da escrita sobre a fala, ou, ainda, a de que os alunos desse nível de escolaridade não são expostos a práticas sociais que pedem um agir por intermédio da oralidade.

A distribuição dos objetivos de aprendizagem entre as "práticas sociais" apresenta desequilíbrio acentuado e apenas 03 práticas (do total de 06) foram contempladas:

Tabela 1 - Práticas sociais e objetivos/objetos de ensino

\begin{tabular}{lccccc}
\hline \multirow{2}{*}{ Práticas sociais } & \multicolumn{2}{c}{ Objetivos / Anos do EM } & \multirow{2}{*}{ Totais } \\
\cline { 2 - 4 } & $\mathbf{1 0}^{\mathbf{2}}$ & $\mathbf{2 0}^{\mathbf{0}}$ & $\mathbf{3}^{\mathbf{0}}$ & \\
\hline Político-Cidadãs & 03 & 02 & 03 & 08 \\
\hline Investigativas & 01 & - & - & 01 \\
\hline do Mundo do Trabalho & - & 01 & - & 01 \\
\hline
\end{tabular}

Fonte: a autora, elaborado a partir de Brasil (2015, p. 61-66)

Podemos observar que o maior número de objetivos de aprendizagem para o ensino da modalidade falada da língua foi direcionado às práticas político- 
cidadãs - $08-$, às demais foi direcionado apenas 01 , evidenciando que essa opção da BNCC pela distribuição dos objetos por práticas pode não ser a mais adequada, pois é incoerente e não representa a realidade do aluno do EM. Como explicar que os estudantes dessa etapa não são, ou são muito pouco, expostos a práticas investigativas ou artístico-literárias que envolvem a oralidade? Por que um número de objetivos relacionados às práticas político-cidadãs tão superior ao número das demais?

Atentando para os objetivos de aprendizagem atribuídos a essa prática majoritária, percebemos que 05 deles se referem a textos do grupo do argumentar, o que parece indicar uma tendência na organização desses objetivos por agrupamentos de textos/gêneros, a partir das tipologias textuais, segundo as "práticas sociais" propostas, o que resulta uma classificação também artificial, pois essa organização cria a falsa impressão de que os falantes argumentam apenas nas práticas político-cidadãs. Isso também explicaria o número bem maior de objetivos nessa prática social. Essa distribuição também parece revelar um critério de progressão linear desses objetivos, bastante cristalizado no ensino: a organização dos conteúdos de acordo com um suposto crescente de dificuldade considerando-se as tipologias textuais - descrição, narração e argumentação (nessa ordem de aprendizagem). Talvez isso também explique a predominância de objetivos de aprendizagem voltados para a argumentação, no EM.

Para a categorização e análise dos objetivos para o ensino da língua falada, utilizamos a proposta de Magalhães (2008) e de Melo e Cavalcante (2007), conforme explicitado na fundamentação teórica e nos procedimentos metodológicos da pesquisa. Assim, os dados foram classificados de acordo com as categorias: escuta e produção de textos orais. Os resultados são os seguintes: 
Quadro 5 - Categorização dos objetivos de aprendizagem para o ensino da modalidade oral

\begin{tabular}{|c|c|}
\hline Categorias & Objetivos de Aprendizagem - EM \\
\hline $\begin{array}{l}\text { E } \\
\text { S } \\
\text { C } \\
\text { U } \\
T \\
\text { A }\end{array}$ & $\begin{array}{l}\text { LILP1007. Interpretar textos (orais e escritos) da esfera jornalística voltados } \\
\text { ao relato de acontecimentos (como notícias e reportagens), analisando } \\
\text { aspectos relativos ao tratamento da informação (como a ordenação de } \\
\text { eventos, as escolhas lexicais, o efeito de imparcialidade do relato). } \\
\text { LILP1008. Reconhecer os componentes de uma estrutura argumentativa } \\
\text { (como contextualização, hipóteses, tese, argumento, contra-argumento, } \\
\text { conclusão) e identificar diferentes procedimentos argumentativos, em gêneros } \\
\text { como editoriais, debates televisivos, entrevistas etc. } \\
\text { LILP2014. Analisar o gênero entrevista de trabalho: o conteúdo (o que se } \\
\text { fala), como se fala (as convenções do discurso), a relação dos interlocutores } \\
\text { (os papéis desempenhados pelo entrevistado e entrevistador), a linguagem } \\
\text { corporal, a fluência verbal, compreendendo a entrevista como ferramenta } \\
\text { importante em processos seletivos. } \\
\text { LILP2005. Analisar percurso argumentativo de gêneros orais e escritos da } \\
\text { ordem do argumentar, considerando seus recursos coesivos (operadores } \\
\text { argumentativos de causalidade, oposição, conclusão, ressalva etc.) e, no caso } \\
\text { do texto escrito, também os critérios de paragrafação. } \\
\text { LILP2004. Analisara estrutura composicional de textos da esfera jornalística } \\
\text { voltados ao relato de acontecimentos (como notícias, reportagens, } \\
\text { entrevistas), considerando sua veiculação em diferentes suportes e mídias. } \\
\text { LILP3004. Comparar textos da esfera jornalística voltados ao relato de } \\
\text { acontecimentos (como notícias, reportagens, entrevistas) veiculados em } \\
\text { diferentes mídias (impressa, audiovisual, digital), considerando semelhanças e } \\
\text { diferenças no tratamento da informação. } \\
\text { LILP3005. Analisar em textos argumentativos orais e escritos o uso } \\
\text { estratégico de recursos persuasivos, como a elaboração do título, a explicitação } \\
\text { ou a ocultação de fontes de informação, o uso de recursos de assertividade ou } \\
\text { atenuação de posicionamentos assumidos. }\end{array}$ \\
\hline $\begin{array}{l}\mathbf{P} \\
\mathbf{R} \\
\mathbf{0} \\
\mathbf{D} \\
\mathbf{U} \\
\mathbf{C} \\
\tilde{\mathbf{A}} \\
\mathbf{0}\end{array}$ & $\begin{array}{l}\text { LILP1010. Produzir textos argumentativos orais e escritos, atentando } \\
\text { especialmente para a utilização de diferentes procedimentos argumentativos } \\
\text { (como exemplificação, citação de autoridade, exposição de dados empíricos). } \\
\text { LILP3006. Produzir textos argumentativos e contra-argumentativos orais e } \\
\text { escritos, atentando para estratégias de persuasão como a elaboração do título, } \\
\text { recursos de assertividade ou atenuação dos posicionamentos). } \\
\text { LILP1013. Produzir roteiros para exposição oral de resultados de estudos e } \\
\text { pesquisas em seminários, feiras de ciências e outros eventos escolares e } \\
\text { acadêmicos, bem como avaliar a atuação nas exposições orais próprias e dos } \\
\text { colegas. }\end{array}$ \\
\hline
\end{tabular}

Fonte: a autora, elaborado a partir de Brasil (2015, p. 61-66; grifos nossos)

\section{Quanto à escuta}

Para a análise dos objetivos categorizados dessa forma, consideramos apropriados, conforme nosso referencial teórico-metodológico, os que poderão 
levar o aluno a analisar as marcas típicas da modalidade oral, em situações reais de uso. São aqueles que contemplam: a linguagem em função do contexto; diferenças em função dos interlocutores envolvidos; conhecimento da estrutura de participação dos eventos linguísticos em questão; apreensão do tema.

Dos 10 objetivos que privilegiam essa modalidade para ensino de língua portuguesa no EM, presentes na BNCC, 07 podem ser viabilizados pela escuta de textos (Quadro 5).

O objetivo 2014 propõe a análise do gênero "entrevista de trabalho". Parece esboçar como meta a análise de marcas da oralidade e considerar a situação de uso da língua ao propor a análise de alguns aspectos da ordem do linguístico ("fluência verbal"), do paralinguístico ("a linguagem corporal") e do extralinguístico ("relação interlocutores"), bem como apreensão do tema ("o que fala") e a preocupação com a situação de interlocução (a importância do gênero "entrevista de trabalho em processos seletivos").

O objetivo 1008 foi incluído em nossa categorização porque cita o gênero "debate televisivo". Tem como foco a estrutura clássica de alguns gêneros argumentativos - "hipótese, tese, argumento, contra-argumento, conclusão"-, ou seja, a estrutura composicional do gênero. Também demonstra preocupação com o contexto de produção, porém, equivocadamente, considera-o parte da estrutura do gênero e não como situação comunicativa determinante da sua escolha. Do modo como esse objetivo está proposto, parece-nos também que o esperado é apenas a extração dessas informações ("reconhecer" e "identificar") sem a necessidade de reflexão, o que não proporciona a ampliação dos conhecimentos de linguagem oral $e$, consequentemente, não promove 0 desenvolvimento do aluno.

Os objetivos 2005 e 3005 também se referem à argumentação, mas a partir do tipo de texto argumentativo. O cerne do primeiro (2005) é a coesão textual, contudo, embora o objetivo também englobe "textos orais", ele não se refere a marcadores conversacionais, unidades típicas da fala que auxiliam na construção do texto falado, na coesão, na coerência e na progressão textual. 0 
objetivo menciona apenas operadores argumentativos ${ }^{18}$. O segundo (3005) focaliza aspectos do tipo textual argumentativo - o uso de recursos linguísticos para sua construção: "elaboração do título, explicitação ou ocultação de fontes de informação, uso de recursos de assertividade ou atenuação de posicionamentos assumidos". A impressão é a de que ele foi pensado apenas para a escrita e que a menção a gêneros orais é um detalhe que precisava constar.

Os objetivos 1007, 2004 e 3004 reportam-se a esferas em que circulam os gêneros ("textos da esfera jornalística") e a gêneros ("notícia, reportagem, entrevistas"). O primeiro e o terceiro (1007 e 3004) o fazem por meio do "tratamento da informação", considerando aspectos linguísticos, o modo como são organizados nos gêneros citados e os efeitos de sentido que produzem, especificamente, o de "imparcialidade". Trata-se, portanto, do enfoque da estrutura composicional e do estilo desses gêneros. O segundo objetivo (2004) contempla as diferenças da estrutura composicional dos gêneros jornalísticos, a partir da mudança do suporte e da mídia em que são veiculados. Optamos por incluir esse objetivo de aprendizagem em nossa classificação, porque, além de os gêneros citados também serem veiculados com o uso da modalidade oral, foi mencionada a "mudança de suporte e mídia". Não há menção às situações de produção/recepção desses gêneros.

Dos 07 objetivos de aprendizagem passíveis de serem viabilizados pela escuta, apenas 01 (2014) parece possibilitar a exposição do aluno a situações reais de interlocução e de uso da língua falada, os demais consideram a análise da estrutura e do estilo dos gêneros, além de alguns aspectos linguísticos com foco em recursos coesivos do texto. A preferência foi dada a gêneros da esfera jornalística, particularmente, notícia, reportagem e entrevista; e a tipos de texto, exclusivamente, o tipo argumentativo, evidenciando um descompasso, pois o tipo predominante nos gêneros jornalísticos considerados corresponde à narração e

\footnotetext{
${ }^{18}$ Segundo Oliveira (2003), os operadores argumentativos também são elementos coesivos e contribuem para a progressão textual, porém são alusivos ao texto escrito.
} 
ao diálogo. Essa seleção também denota certa confusão conceitual entre tipologia textual e gêneros de texto ou mescla de critérios de escolha/seleção dos objetivos referentes ao ensino da oralidade no EM. Algumas propostas não requerem a reflexão, mas apenas a extração de informações do texto.

\section{Quanto à produção}

Seguindo nosso aporte teórico-metodológico, para a análise dos objetivos de aprendizagem categorizados dessa maneira, consideramos apropriados os que poderão possibilitar ao aluno a produção de gêneros e de seus suportes, em situações reais de interlocução; e a preparação prévia para o uso de gêneros orais e seu uso específico. Objetivos que: orientem sobre procedimentos para ancorar a fala do locutor, em função da situação de comunicação, do público, da estrutura de participação dos eventos linguísticos em questão e das especificidades do gênero.

Dos 10 objetivos que contemplam a modalidade oral da língua, presentes na BNCC, 03 (1010, 3006 e 1013) referem-se à produção textual (Quadro 5).

Os objetivos de aprendizagem 1010 e 3006 estão focados em um dos aspectos da produção de textos do tipo argumentativo: na construção de "procedimentos argumentativos" e de "estratégias de persuasão" ("exemplificação, citação de autoridade, exposição de dados empíricos, título, recursos de assertividadade/atenuação dos posicionamentos"). Assim, o que está sendo considerado são aspectos linguísticos para a construção de argumentos. Não há menção à situação de comunicação.

O objetivo 1013 trata da produção do gênero "roteiro" para exposição oral, ao que parece como preparação prévia para o uso da fala, pois, ao final, referese à avaliação da "atuação nas exposições orais próprias e dos colegas". Esse objetivo pode suscitar a elaboração de atividades que envolvam o planejamento da fala em função dos aspectos linguísticos, paralinguísticos e extralinguísticos, considerando a situação de comunicação, embora isso não esteja explícito. 
Dos 03 objetivos de aprendizagem passíveis de serem viabilizados pela produção, apenas 01 (1013) parece dirigido especificamente para a preparação prévia para o uso da fala. Os demais focalizam aspectos linguísticos característicos da tipologia argumentativa, ou melhor, da estrutura composicional de gêneros do argumentar. De maneira geral, não são mencionados procedimentos para ancoragem da fala do locutor, em função da situação de comunicação, do público, da estrutura de participação dos eventos linguísticos, e das especificações do gênero como um todo.

A proposta de objetivos de aprendizagem voltados para a produção textual que contemplam a modalidade oral da língua se mostrou bastante reduzida, considerando-se que, durante todo o período do EM, apenas 03 objetivos (Quadro 5) compõem a BNCC com esse propósito. Tal como ocorre na categorização da escuta, na da produção, encontram-se objetivos que denotam um desencontro entre o gênero solicitado (roteiro para exposição oral) e o tipo textual destacado (argumentativo), indicando a mescla de critérios na escolha/seleção dos objetos de ensino. Vale enfatizar ainda que, caso não fique clara a diferença conceitual entre um e outro, isso também prejudicaria a aprendizagem, pois tipos de textos não são práticas de linguagem por meio das quais os usuários da língua agem nas práticas sociais. A tipologia de textos referese a sequências textuais estereotipadas, cuja finalidade é a estruturação do gênero. Ou seja, ela está no nível do texto e não do discurso.

\section{Dos resultados}

A observação geral do texto da BNCC revelou a ausência de esclarecimentos, o que imprime ao Documento um dos aspetos problemáticos quanto a sua estrutura: a inexistência de princípios norteadores ou dos "direitos à aprendizagem" que deveriam configurar essa estrutura, de acordo com o afirmado no primeiro capítulo do Documento; e a falta da especificação (ou de clareza) da filiação teórica que fundamenta conceitos e noções importantes para 
área. Talvez essa última também possa ter sido responsável pelos problemas encontrados quanto ao ensino da modalidade oral.

A observação da estrutura da BNCC apontou uma organização complexa e pouco eficiente, provavelmente, em decorrência da profusão de objetivos gerais, práticas sociais/campos de atuação e objetivos de aprendizagem; e de um detalhamento excessivo e pouco condizente com um Documento proposto como base do currículo escolar em nível nacional, a qual deve representar $60 \%$ dele. A divisão das áreas do conhecimento em componentes curriculares e objetivos parece imprimir a ela uma organização disciplinar, aspecto que contraria a proposta de interdisciplinaridade das áreas e de transdisciplinaridade entre elas (BRASIL, 2012), o que, no caso específico do EM, não contribuiria para mudanças: ainda haveria disciplinas compartimentadas e com excesso de conteúdos.

No caso do componente curricular LP, a proposta inicial de eixos de ensino desaparece em meio aos objetivos de aprendizagem, resultando não apenas na dificuldade de seleção e categorização dos dados para a análise exposta neste artigo, mas também na impossibilidade de relacionar esses objetivos aos objetivos gerais do componente curricular em questão, ou ainda de contemplar específica e claramente a oralidade.

Quanto aos objetivos de aprendizagem propostos para o ensino da modalidade oral da língua portuguesa, a falta de critérios claros para a seleção, a distribuição e a organização desses objetivos nas práticas sociais escolhidas e ao longo dos anos do EM - em contraste com a realidade dos alunos dessa etapa escolar -, bem como a falta de critérios para a progressão curricular, tornaram a proposta, em vários momentos, incoerente e problemática, o que se confirma no desequilíbrio entre objetivos de aprendizagem da modalidade falada e da escrita; na proposição de aprendizagem de gênero textual inadequado a determinado ano do EM; na ênfase no ensino de apenas uma tipologia textual e sem correspondência com o gênero solicitado; na ênfase exagerada no ensino de gêneros de uma única esfera em detrimento de outras; na falta de clareza 
conceitual entre tipos textuais e gêneros de texto; na artificialidade das práticas sociais propostas.

Em relação ao desequilíbrio na proposição de objetivos das duas modalidades, o tratamento dado à oralidade apontou um número bastante reduzido de objetivos de aprendizagem da modalidade oral da língua ao longo dos 03 anos do EM (10 de um total de 45), levando-nos à conclusão de que o Documento valoriza mais a escrita que a fala, pelo menos, nessa etapa de ensino, ignorando que os alunos dos anos finais da EB também estão expostos a práticas sociais que exigem o agir por meio de práticas de linguagens nessa modalidade da língua.

O desaparecimento ou a diluição do eixo de ensino específico, quando da proposição desses objetivos, também levou à inexistência de objetivos que tratassem do continuum fala-escrita (MARCUSCHI, 2001; KOCH, 1997), pois a articulação entre textos orais e escritos, proposta na descrição desse eixo, nos objetivos gerais do componente LP, não é contemplada nos objetivos de aprendizagem; do mesmo modo, as marcas próprias da modalidade falada da língua são muito pouco exploradas, o mesmo acontecendo com as situações de comunicação em que ela é manifestada pelos usuários da língua.

Essas constatações demonstram que a maneira como esses objetivos de aprendizagem foram propostos (e os objetos de ensino que contemplam) não favoreceria, ou favoreceria muito pouco, a formação bimodal (MARCUSCHI, 2001), o desenvolvimento da competência discursiva ou a oralidade letrada do aluno (KATO, 1986) do EM.

\section{Considerações finais}

Nossa proposta foi analisar um dos aspectos da BNCC, mais especificamente, o tratamento dado à oralidade letrada e ao ensino da modalidade oral da língua -, pois, além da relevância do Documento para a 
educação formal do país, temos um interesse pessoal como professora formadora de professores da EB e como pesquisadora da área de Linguística Aplicada.

Para além dos pontos problemáticos observados, reconhecemos o esforço e valorizamos o empenho e a intenção na elaboração de uma base comum curricular para as instituições públicas e particulares do país, com vistas a oportunizar uma educação de qualidade ao alunado brasileiro, tentando superar a distância entre as propostas curriculares dessas instituições e a realidade de vida e de trabalho dos estudantes.

Contudo, a elaboração de um documento normativo da educação, sem a participação efetiva de professores, gestores e alunos, os protagonistas que podem contribuir efetivamente com seus saberes e experiências, parece um dos pontos mais conflituosos desse processo.

Além disso, sabemos que não basta mais um documento oficial para integrar o trabalho do professor, se outros problemas também não forem resolvidos, tais como a falta de recursos, de estruturas, de salários condizentes, de uma carga de trabalho mais justa e produtiva, ou seja, de um sistema que garanta cidadãos com formação de qualidade e condições de trabalho favoráveis.

Com relação à oralidade, nosso objeto de pesquisa, observamos que o tratamento eficiente da modalidade falada da língua parece um pouco distante da BNCC. Concordando com Magalhães (2008), ponderamos que talvez isso esteja ocorrendo, porque dúvidas ainda existem sobre as especificidades de gêneros da oralidade letrada, por exemplo, quanto às características dos eventos linguísticos no continuum fala-escrita e à forma de ensiná-los.

Quanto ao ensino efetivo da modalidade oral, parece-nos que, em geral, os professores já estão cientes da sua importância para o desenvolvimento da competência discursiva do aluno e, consequentemente, da oralidade letrada, entretanto, parece que ainda são poucos os instrumentos que auxiliam na reflexão sobre o que é o oral em toda sua amplitude e como ele pode ser ensinado e avaliado. Essa constatação pode ser confirmada no texto da BNCC. Assim como na primeira versão Documento norteador da educação, ainda são 
poucas e, às vezes, inadequadas ou pouco esclarecedoras as atividades propostas em sala de aula, cujo objetivo seja o ensino sistemático dessa modalidade da língua, conforme ficou demonstrado na análise.

\section{Referências}

BAKHTIN, Mikhail. Estética da criação verbal. São Paulo: Martins Fontes, 2003.

BRASIL. Ministério da Educação. Base nacional comum curricular. Brasília, 2015. Disponível em: <http://basenacionalcomum.mec.gov.br/\#/site/inicio>. Acesso em: nov./2015.

BRASIL. Ministério da Educação. Diretrizes curriculares nacionais gerais para a educação. In: . Diretrizes curriculares nacionais da educação básica. Brasília, 2013.

BRASIL. Ministério da Educação. Diretrizes curriculares nacionais para o ensino médio. Brasília, 2012. Disponível em: <http://portal.mec.gov.br/index.php? option=com_docman\&view=download\&alias=9864-rceb002-12\&category_slug= janeiro-2012-pdf\&Itemid=30192 > . Acesso em: jan./2014.

Brasília, 2000.

Parâmetros curriculares nacionais - ensino médio: língua portuguesa. Brasília, 1997.

Parâmetros curriculares nacionais $-1^{\mathrm{a}}$ a $4^{\mathrm{a}}$ séries: língua portuguesa. . Parâmetros curriculares nacionais - $5^{\mathrm{a}}$ a $8^{\mathrm{a}}$ séries: língua portuguesa. Brasília: MEC, 1998.

BRASIL. Lei no 9.394, de 20 de dezembro de 1996. LDB. Estabelece as diretrizes e bases da educação nacional. Brasília, 1996. Disponível em: <http://www.planalto.gov.br/ccivil_03/leis/L9394.htm>. Acesso em: ago. 2015.

BRONCKART, Jean-Paul. Gêneros de textos, tipos de discurso e sequências: por uma renovação do ensino da produção escrita. Letras, Santa Maria, v. 20, n. 40, p. 163-176, jan./jun. 2010.

CASTILHO, Ataliba Teixeira de. Estudos de língua falada: uma entrevista com Ataliba Teixeira de Castilho. Revista Virtual de Estudos da Linguagem - ReVEL, v. 3, n. 4, mar./2005. Disponível em: <www.revel.inf.br/files/entrevistas/revel_ 4_entrevista_ataliba_teixeira_de_castilho.pdf>. Acesso em: dez. 2015. 
2000.

. A língua falada no ensino de português. 2. ed. São Paulo: Contexto,

. (Org.). Gramática do português falado. Volume I: a ordem. Campinas: UNICAMP/FAPESP, 1990. (Série Pesquisas).

. (Org.). Gramática do português falado-volume III: as Abordagens.

Campinas: UNICAMP/FAPESP, 1993. (Série Pesquisas).

CASTILHO, Ataliba Teixeira de.; BASÍLIO, Margarida. (Orgs.). Gramática do português falado - volume IV: estudos e prescritivos. Campinas:

UNICAMP/FAPESP, 1996. (Série Pesquisas).

DIONÍSIO, Angela Paiva; MACHADO, Anna Raquel; BEZERRA, Maria Auxiliadora. Gêneros textuais e ensino. 2. ed. Rio de Janeiro: Lucerna, 2003.

DIONÍSIO, Angela Paiva. Análise da conversação. In: MUSSALIM, Fernanda; BENTES, Anna Christina. (Org.). Introdução à linguística: domínios e fronteiras. 5. ed. São Paulo: Cortez, 2006.

DOLZ, Joaquim; SCHNEUWLY, Bernard. O oral como texto: como construir um objeto de ensino. In: SCHNEUWLY, Bernard; DOLZ, Joaquim. Gêneros orais e escritos na escola. Campinas: Mercado das Letras, 2004.

GENOUVRIER, Emile; PEYTARD, Jean. Linguística e ensino de português. Tradução Rodolfo Ilari. Coimbra: Almedina, 1974.

GNERRE, Maurizio. Linguagem, escrita e poder. 3. ed. São Paulo: Martins Fontes, 1991.

ILARI; Rodolfo (Org.). Gramática do português falado - volume II: níveis de análise linguística. Campinas: UNICAMP, 1992. (Série Pesquisas).

KATO, Mary. No mundo da escrita: uma perspectiva psicolinguística. 2. ed. São Paulo: Ática, 1986.

. (Org.). Gramática do português falado - volume V: convergências. Campinas: UNICAMP/FAPESP, 1996. (Série Pesquisas).

KLEIMAN, Angela. Letramento: práticas relacionadas com a escrita em toda atividade da vida social. Linguagem em (Dis)curso-LemD, v. 8, n. 3, p. 487517, set./dez. 2008.

- (Org). Os significados do letramento: uma nova perspectiva sobre a prática social da escrita. Campinas: Mercado das Letras, 1995.

KOCH, Ingedore Villaça. $A$ inter-ação pela linguagem. São Paulo: Contexto, 1998. 
. O texto e a construção dos sentidos. São Paulo: Contexto, 1997.

. (Org.). Gramática do português falado - volume VI: desenvolvimentos. Campinas: UNICAMP/FAPESP, 1996. (Série Pesquisas).

MAGALHÃES, Tânia Guedes. Por uma pedagogia do oral. Signum, Londrina, v. 11, n. 2, p. 137-153, dez. 2008.

MARCUSCHI, Luiz Antônio. Produção textual, análise de gêneros e compreensão. São Paulo: Parábola, 2008.

. Análise da conversação. 5. ed. São Paulo: Ática, 2006a.

. Gêneros textuais: configuração, dinamicidade e circulação. In:

KARWOSKI, Acir Mário; GAYDECZKA, Beatriz; BRITO, Karim Siebeneicher. (Org.). Gêneros textuais: reflexões e ensino. 2. ed. Rio de Janeiro: Lucerna, 2006b.

. Gêneros textuais: definição e funcionalidade. In: DIONÍSIO, Angela Paiva; MACHADO, Anna Raquel; BEZERRA, Maria Auxiliadora. Gêneros textuais e ensino. 2. ed. Rio de Janeiro: Lucerna, 2003.

. Da fala para a e escrita: atividades de retextualização. 2. ed. São Paulo: Cortez, 2001.

MARINHO, Marildes. Currículos da escola brasileira: elementos para uma análise discursiva. Revista Portuguesa de Educação. Braga, v. 20, n. 1, p. 163-189, 2007.

MELO, Cristina Teixeira Vieira de.; CAVALCANTE, Marianne Carvalho Bezerra. Superando os obstáculos de avaliar a oralidade. In: MARCUSCHI, Beth; SUASSUNA, Lívia. (Org.). Avaliação em língua portuguesa: contribuições para a prática pedagógica. Belo Horizonte: Autêntica, 2007.

OLIVEIRA, Esther Gomes de. Aspectos diferenciais dos operadores argumentativos e dos marcadores discursivos. In: MACEDO, Joselice; ROCHA, Maria José Campos; SANTANA NETO, João Antônio de. (Org.). Discursos em análises. Salvador: Universidade Católica de Salvador, Instituto de Letras, 2003.

RAMOS, Jânia Martins. O espaço da oralidade na sala de aula. São Paulo: Martins Fontes, 1999.

RODRIGUES, Ayron Dall'Igna. Tarefas da linguística no Brasil. Estudos Linguísticos. Revista Brasileira de Linguística Teórica e Aplicada. São Paulo, v. 1, n. 1, p. 4-15, jul. 1966. 
SCHNEUWLY, Bernard. Palavra e ficcionalização: um caminho para o ensino da linguagem oral. In: SCHNEUWLY, Bernard; DOLZ, Joaquim. Gêneros orais e escritos na escola. Campinas: Mercado das Letras, 2004. 